\title{
Keeping it real: an action research investigation into using concrete objects to teach algebra
}

Book or Report Section

Accepted Version

Curtis, F. (2017) Keeping it real: an action research investigation into using concrete objects to teach algebra. In: Research Methods Cases - Education. Sage. ISBN 9781473991903 doi: https://doi.org/10.4135/9781473991903 Available at http://centaur.reading.ac.uk/65909/

It is advisable to refer to the publisher's version if you intend to cite from the work. See Guidance on citing.

To link to this article DOI: http://dx.doi.org/10.4135/9781473991903

Publisher: Sage

All outputs in CentAUR are protected by Intellectual Property Rights law, including copyright law. Copyright and IPR is retained by the creators or other copyright holders. Terms and conditions for use of this material are defined in the End User Agreement. 


\section{www.reading.ac.uk/centaur}

\section{CentAUR}

Central Archive at the University of Reading

Reading's research outputs online 


\section{SAGE Research Methods Case Education Submission for Consideration}

\section{Case Title}

"Keeping it real: An action research investigation into using concrete objects to teach algebra"

\section{Author Name(s)}

Fiona Curtis

\section{Author Affiliation \& Country of Affiliation}

University of Reading, United Kingdom

\section{Lead Author Email Address}

f.r.curtis@reading.ac.uk

\section{Discipline: D2 [please do not alter]}

\section{Sub-discipline}

Secondary Education [SD-Edu-14]

\section{Academic Level}

Postgraduate

\section{Contributor Biographies}

Fiona Curtis has been a lecturer at the University of Reading since 2015. Prior to this appointment she was a maths teacher at secondary schools, with responsibilities for various aspects of key stages 4 and 5 (14- 16 year olds and 17-18 year olds). She is subject leader of Secondary Maths Initial Teacher Training at the University of Reading and also teaches on other teacher training courses there. She contributes to the Masters and Doctoral programmes, leading the module on the EdD course entitled 'The Psychology of Education and Learning'. She contributed to a workshop in Algeria on doctoral research proposals and supervises three doctoral students who are investigating various aspects of teacher development and expertise. 
Areas of research interest include the teaching of maths and statistics in unconventional ways, the gender imbalance in the study of maths at higher levels, and emotional and affective reactions to being taught. She is on the local ATM committee and has presented at BERA in 2015 and twice at BSRLM in 2015 and 2016.

\title{
Published Articles
}

Curtis, F. (2015). Challenge: always a good thing? Proceedings of the British Society for Research into Learning Mathematics, 35, (2), 7-12.

\begin{abstract}
English schoolchildren do not fare well in international comparisons of mathematical, particularly algebraic, ability. I believe that this is at least partly due to algebra being traditionally taught using only symbols, ignoring the enactive-iconic-symbolic trajectory described by Jerome Bruner, which says that experiencing the way in which concrete objects behave makes it possible to learn in the abstract. I believed algebraic understanding would be enhanced by students working with concrete objects that they would be able to connect to algebraic ideas, for example using a giftcard to represent a value that existed but was unknown to the holder.

The conventional research approaches of positivist or interpretivist did not seem to me to reflect a dynamic reality in which my role was not a dispassionate external observer or interpreter. Action research is a critical theory approach that embraces the individuality of the researcher/practitioner, by recognizing practical knowledge in context (praxis), allowing their understanding of the situation being researched to be developed from cycles of action, reflection and adjustment of their own practice. The benefits to me were the flexibility of reflecting and making changes, empowerment to challenge the status quo, and substantial insight into how children learn. The disadvantages in terms of generalisability and lack of conclusiveness are always factors in this sort of research, but the difficulty of creating materials, managing data and interpreting results were more challenging than I had anticipated. My work led to the development of teaching material that has already had impact beyond my own practice.
\end{abstract}

\section{Learning Outcomes}

By the end of this case students should be able to:

- Recognize the key features of action research 
- Understand the methodological approach that gives rise to it

- Understand how the ideology referred to in the literature links to research design

- Interpret the results and consider whether adjustments to the research design would have affected the results reported by the researcher

- Consider whether the disadvantages of this form of research outweigh the advantages

\section{Case Study}

\section{Keeping it real: An action research investigation into using concrete objects to teach algebra}

Why do children find algebra so difficult? It is a question that every secondary maths teacher faces as she sifts through the errors and misconceptions that constitute the average English student's response to lessons in early algebra. Behind the oft-touted statistics of England's poor mathematical placing in international comparison lie even more damning results for algebraic performance eighth graders were $10^{\text {th }}$ of 25 countries for mathematics generally, but $17^{\text {th }}$ for algebra (Mullis, Martin, Foy \& Arora, 2012). The government's response to the problem is to introduce algebra into the primary curriculum, despite traditional notions that algebra should only be taught to adolescents and older, who are considered to be developmentally ready for the logical thought necessary for working in the abstract (Piaget, 1952).

To investigate how I could improve my teaching of algebra I turned to action research. Action research is a research method in which the researcher identifies an area of her own practice that she would like to improve, and undertakes cycles of interventions, reflecting and adjusting at each turn. The research can be technical or practical in focus, (looking at what works within the existing system, without addressing issues relating to the status quo), or it can be emancipatory, that is it is intended to enable change to be made and felt by those who seek it, with potential to unsettle the status quo (Kemmis, 1993). It is a methodology that arises from frustration with both positivist and interpretivist ontologies, in which the research is placed as observing and/or interpreting a situation, and seeks instead to recognize that the researcher is part of the situation itself and the social consciousness that created it. Action research rejects a divide between theory and practice and looks for answers in praxis - practical knowledge in context (Carr \& Kemmis, 1986 ). 


\section{Methodology}

Action research requires systematic reflection informed by literature and tested in practice (Norton, 2009). It is traditionally done as a democratic form of research by a group of people, in which the discourse between parties of equal weighting allows those parties to better understand their actions and validate their interpretations, in line with Habermas' (in Carr \& Kemmis, 1986) ideas of how to identify consensual truth. An individual can engage in action research using self-reflection to split apart the roles of practitioner and researcher in a process a little like psychoanalysis, designed to liberate them from "irrational compulsions of their individual history" (Carr \& Kemmis, 1986, p.138). The process starts with a critique of one's normal practice.

I assessed my lessons as being calm and focused, students being able to do what I had just showed them how to do, yet failing to make substantial progress in subsequent tests. I realized that students did not maximise their learning because they made no personal connection with the material, had not integrated it into a network of understanding, and consequently forgot it soon after the lesson. For example solving equations was taught by demonstrating the inverse operations that isolate a variable, working through examples at the board and then student practice of similar questions. I realized that this reflected a profound imbalance of power, in which students' interpretations, experiences and wishes were not recognised - why might they want to isolate a variable? Why is this considered to be "solving" (a word perhaps associated in the students' minds with detective dramas)? What was wrong with their instinctive response of guessing and checking? Furthermore it was biased towards those who possessed my cultural capital (Bourdieu, 1973): children who were culturally accepting of learning 'for its own sake', delayed gratification, resilience, and gaining teacher approval were more likely to accommodate the information than those who were not culturally imbued with these principles. I did not meet the students' needs and did not attempt to connect with their values.

I therefore started to look for a way of teaching that allowed students to make sense of their learning and connect with their lived experiences, thus liberating them from a passive role in learning, and liberating me from my cycle of planning, delivering and testing in a way that has no relevance to the intended audience. My analytical lens was provided by Bruner's (1966) work on how students learn, in which he explains the development of children's understanding from recognising how objects respond to manual manipulation, to understanding how things work in the abstract, via a visual stage in which the use of pictures stands in for the actual objects. This enactiveiconic-symbolic trajectory is not tightly associated with a child's age. Different challenges will be responded to in an enactive or iconic or symbolic way, and often a phase may be returned to for 
consolidation of understanding. Bruner's theory suggests any subject can be presented in a format that allows a child access to the first step. I turned to manipulatives (concrete objects that allow hands-on learning) and focused on making connections between the way the students knew these materials behaved and abstract algebra.

The question of how to judge the success or otherwise of an action research project is challenging. Instead of being able to rely on measures of validity and reliability I accepted Judith Bell's (2005) preference for 'relatability', ie findings are judged to the extent that others can relate to them. This focus on others' recognition of the usefulness of the work is hard to monitor, but I can report anecdotally that colleagues and fellow teachers recognise the problems described in my work, and have found the resources developed as a consequence to be useful. McNiff and Whitehead's (2010) evaluative tool requires the researcher to judge in terms of whether her practice has changed to be more in line with her values. I can report that the focus on student need and understanding rather than imposed transmission reflects my values of what leads to effective learning, as well as what is ethical in terms of power relations.

\section{Methods}

The research question was: can concrete objects help students learn early algebra? This was explored through a number of sub-questions regarding student attitudes, benefits and problems with manipulative use, and the connection between appropriate use of concrete objects and successful formal methods.

The students in this research came from the school in which I worked. While this is not a random sample as required by a positivist approach, it is appropriate for action research, in which one addresses one's own practice. The first two intervention cohorts were four groups of two to three year 10 students (14-15 year olds) who volunteered themselves from a mixed ability class that was not expected to gain a $\mathrm{C}$ or above at GCSE, the exam taken by 16 year olds in the UK. The third cohort consisted of two year 7 classes (11-12 year olds) of similar attainment, one of which was used as a control group. The classes were chosen for convenience, and the students and their parents decided whether they wanted to take part in the intervention, following ethics guidance.

The intervention consisted of fortnightly lessons over the period of one term with the first two groups of three students, the same over the subsequent term for the second two groups consisting of two students each, and four lessons in the summer term for the two classes that constituted the third cohort, with one or two exceptions who did not give their consent. The first groups used a 
variety of concrete objects intended to mimic algebraic ideas across the early algebra syllabus, the second groups used one embodiment of an algebraic idea (an icon representing a playing card, used virtually on computer tablets) across a slightly more restricted syllabus, and the third groups used counters to represent money in studying sequences and linear graphs in terms of "pay deals" - fixed and variable elements of a salary.

Action research can use quantitative or qualitative methods - I chose to use both in a mixed methods design. Quantitative data was collected from a survey of school teachers regarding their use of manipulatives in order to see how common their usage was, an inventory about attitudes to algebra given to groups of students prior to intervention, and pre- and post-tests.

- The online anonymous survey was written by me, focusing on when and with whom manipulatives were used in algebra lessons. It was distributed to the maths department of 11 secondary schools with varying characteristics: independent/state/academies/single sex/selective in order to gain the view of as wide a variety of teachers as possible. The schools were local to my own so the sample was a convenience sample, but I do not believe that geography would be a factor in the use of manipulatives so that limitation was condoned. This data was analysed using descriptive data, as there was no significant inferential data. Knowledge of the existing state of affairs was valuable in providing the context to my research.

- The inventory used was the Tapia and Marsh "Attitude towards mathematics inventory" (Tapia and Marsh, 2004, appendix 1), but with the word 'algebra' substituted for the word 'mathematics', with the authors' permission. This measure has high validity and reliability and has been used in many similar projects. This data was analysed using descriptive data and inferential data, particularly looking at correlations between different attitudes.

- The pre- and post-tests were written by me using questions that I felt were representative of the level of algebra these groups of students should be familiar with based on their previous attainment and targets. The results were analysed using descriptive data and inferential data, and also used qualitatively to investigate the types of errors students made.

Qualitative data was effectively three case studies using transcriptions from the intervention lessons.

- The transcriptions were examined for themes reflected in the literature (deductive) and for any other themes not previously identified (inductive). Quotations were used to reflect the student voice. 
It was hoped that using a mixed methods approach would provide triangulation and also allow each to fill the weaknesses inherent in the other.

\section{Results}

The concrete objects I chose varied greatly in the extent to which students recognised the way they were intended to mimic algebraic features. Collecting terms using playing cards and solving equations using giftcards were fairly successful:

(solving $4 c+6=6 c$ ): "Well, we can take two cards away again and another two cards away, another two cards away, another two cards away and it's easy - that's just going to be 3." (Adam)

However representing sequences by cutting up number lines confused the students, and expanding and factorising using algebra tiles was disastrous, and caused them to lose confidence:

"I don't know, it's all just a vague blur" (Ben)

Using icons on tablets was more successful, partly because I stuck with the same idea throughout (playing cards), and partly because I was less ambitious in the parts of the curriculum I attempted to cover. Representing substitution, equation of a line and sequences using counters as units of money in various pay deals with fixed and variable elements was very successful, but the counters themselves were not as significant as the idea of pay deals. Students were able to interpret $3 x+1$ as an unknown number of hours being paid at $f 3$ an hour, plus a bonus of $f 1$, without needing counters to map out the answer.

"The counters made me slow down a bit but they made me understand the question more" (year 7 student)

Perhaps more significant than my understanding of how the manipulatives could be used was my understanding of how students learned. The poignancy of not understanding was expressed by one student:

"(it) makes you feel really alone, like everyone's flying off and you're left behind" (Charles)

and their disconnection between their studies and the real world:

"To me it's just teaching, it's just like filling up, and no one every says 'oh, you'll use this for this and this job' (Edward) 
Their struggles with number work were evident:

"All the numbers are flying around in my head, and I'm like woah, woah, woah, and if I had it out in front of me, it's easier"'" (Adam)

and their understanding of directed number was particularly weak:

(calculating $-2+7$ by counting on from -2 using fingers) "does it go minus zero?" (Ian)

This understanding was very significant to my practice. I realized the extent of the students' problems, their alienation from the subject and the emotional impact these experiences created. I questioned the constant drive for "challenge" in the classroom which I suggested had led to these students never being allowed to settle with an idea, and never being given time to recognize their own understanding (Curtis, 2015).

The conclusions I drew were that manipulatives are useful in providing a trail of physical evidence to assist working memory, and can be helpful in enabling self-efficacy.

"When you're writing it out you don't actually have it physically in your hand, and like when you move it, so I'm moving and I've got, like two cards and take one card away and I've got one. And so I know, I can see how it works." (Adam)

They are helpful when they conjure up a meaningful connection to lived experience, for example using a card marked IOU to indicate a debt or negative value meant that Charles could access his intuitive understanding:

"Researcher: When you take away -1 is that bad or good?

Charles: $\quad$ bad, no it's good, good, because you take away the IOU"

Students generally enjoy using them, but their use can be time consuming and difficult to manage. They may prompt students to recognise that their previous understanding is inadequate ('cognitive conflict') but that does not necessarily mean that students will go on to remedy this deficiency. They can effectively model abstract ideas but that does not mean that written algorithms will necessarily follow, nor will procedural fluency. In particular the notation of algebra is a language that needs to be learned in its own right.

\section{Practical lessons learned}


Conducting action research is a very rewarding and empowering enterprise, but surprisingly and persistently challenging. I shall outline the rewards before writing in more detail of the challenges.

\section{Rewards}

1. Control

By its very nature this form of research demands that it is the researcher who decides and justifies what is and is not to be part of the research. This meant that I could work with a small convenience sample for example, and not have to follow positivist experimental procedure.

2. Flexibility

Action research is contextual and is intended to allow the research to work within the setting as it reveals itself. This meant that when I felt another direction was called for, I could pursue it.

3. Emancipation

The survey showed me that accepted practice is to teach algebra symbolically without reference to lived experience. A critical perspective on this would say that as a consequence, algebra serves a gatekeeper role in filtering certain types of thinkers, or those possessing a particular type of cultural capital. This investigation showed me that it was possible to break free of these conventions and give access to this important subject to those who are not comfortable with abstract ideas.

4. Relationships

As the students gained in confidence and skill I shared their pleasure at being successful in a subject in which they had experienced only uncertainty. The flip side of this is the distress I felt when the students could not consolidate their results when tested, as each of us felt we had let the other one down.

5. Pedagogic knowledge

The opportunity of drilling down into what conceptions students bring to bear on their studies is one that should be snatched up by every teacher. The extent of areas that caused difficulties was revelatory. Basic arithmetic was far less secure than I had imagined, the concept of directed numbers was unimaginably tenuous. Possibly even more significant was 
the impact of student emotion and desire to avoid failing and/or looking stupid. Although I had taught for many years I realised that my perceptions had been shaped by my perspective as a teacher, rather than attempting to understand students' perspectives as learners. This new lens was enormously powerful.

\section{Challenges}

1. Validity

Action research is not a positivist research method and therefore it is not appropriate to judge outcomes in terms of comparing group $A$ results with group $B$ results, finding a difference, and asserting a causal relationship, for example by having a control group in the work with the year 10s so that I could have seen if any improvement was due to the manipulative content rather than simply additional lessons. While this sort of data can seem very powerful it denies the uniqueness of any group of individuals and implies a control of variables that cannot exist. For example students who were prepared to engage in additional study would not be typical of students as a population, so the results would not have been comparable with students who were not prepared to engage in additional study. Similarly positivist research would have rejected the provision of tea and biscuits to encourage the students to attend, as well as ensure that the students did not find these lessons stressful, as these different conditions could have been a reason for improved results.

Furthermore I felt that students who were prepared to take extra lessons deserved to have the material that I thought would best serve them, so to give one group the very teaching that I was dissatisfied with was unethical.

2. Concrete (or virtual) representations of abstract ideas I had intended the manipulatives to be so recognisable that students would be able to use them without instruction, but this was not the case. For example in using giftcards to solve equations I expected students to recognise that if child A receiving a giftcard $+£ 5$ had been given the same value as child $B$ receiving $f 10$, the known $f 5$ of each child could be matched and the remainder must be equivalent. However their lack of numeracy skills meant that they could not imagine giftcard $+£ 5=£ 10$ without first exchanging the $£ 10$ note for two $£ 5$ notes so that they could physically match like for like. I also assumed that students would think that when an example used more than one giftcard, each giftcard would be of equal 
value, but the students did not assume that. Similarly I assumed they would realise that in another scenario the giftcard could be worth a different amount, but they assumed that the giftcard was the same value as it had been found to be in the previous example. This made me realise that although I had tried to create manipulatives that corresponded to the real world, I was actually carrying algebraic conventions over which the students did not share.

3. Data

Case studies rely on having material to record. My research was challenged in this respect in two ways. A student in the Spring intervention seemed to be enjoying the lessons and making good progress when he received a note informing him that he was required to see the deputy head. I do not know what the meeting was about but he returned very subdued and did not take part in the remainder of the session, and he did not turn up for subsequent sessions. As this grouping had happened to be a group of two, this left the other student feeling very exposed and uncomfortable, but luckily a student who had taken part in the Autumn intervention asked to return, or my intervention may have had to end.

The second challenge occurred in the second cycle of the research. The first cycle had indicated shortcomings with the material and I decided to use virtual manipulatives instead, ie using icons on tablet computers. The trouble with this is that students had very little need to speak, and I had no way of recording their movements. This limited the data I collected from the second cycle to my assumptions of their thought processes.

4. Qualitative data

The transcription of the audio recording was extremely difficult. Several students talked at the same time, or were indistinct, or did not communicate by speech but by body language or writing. Even when the words could be heard I had to make a decision about how to report the intonation, as that was a matter of interpretation. One particular section serves as an example of this: the assistant head had come into the room and was talking to the students about whether they valued the lessons, and one said that he was only there for the biscuits. I laboured hard over whether that should be considered as an indication that he found the lessons to be valueless, or that he particularly appreciated the consideration demonstrated by providing biscuits, or an attempt to bolster his identity by making it clear that he wasn't the sort of person to voluntarily study, or a way of ingratiating himself with the assistant head to whom he wanted to say something or a way of showing his level of 
comfort by being able to make a joke. I actually think it was the last of these, but have to rely on my familiarity with the student and the context.

Coding is known to be hard but I found it very challenging because the students' words were imprecise and about a variety of topics, rather than the answer to an interview question. For example in the following exchange Ben's response that $-5+4$ is one is correct in terms of its magnitude, but he did not feel it necessary to identify the sign:

"Researcher: That's right I'm adding them all up, so $-5+4 \ldots$

Ben: $\quad$ You're left with one"

Should this be coded as an error? And if so, an error of arithmetic or of communication? He subsequently agreed with another student that it was negative one - did that affect my coding? I had to go through the transcripts many times before I believed I had coded consistently. It was particularly hard to show the absence of something, for example I believed that the students were less anxious about the work than they normally were but they rarely said anything that showed this. This was where I included references to body language, for example one student worked silently but with a broad smile on her face which showed me that she was not experiencing anxiety. If I were to do this investigation again I would enlist the help of collaborators so that these decisions could benefit from another perspective.

5. Results

I enjoyed working with the students in the first cycle and in general they were very successful in what they were doing so I had high hopes for the test. It was disastrous! Progress was minimal. My initial reasoning was that this was because the students had not wanted to ask to use the manipulatives, so in the second cycle I wrote the test for the computer tablet so that the virtual manipulatives were built in. This made no difference, again the test results were very poor. I had to accept that although the manipulatives seemed to help with understanding, manipulative use alone was not enough to ensure confidence in so many different topics in a short space of time.

The problem with the third group of students was the opposite. The intervention group made great progress but so did the control group. Although this could be a result of the 'Hawthorne effect' (ie when the knowledge of being researched causes subjects to change behaviour: Merrett, 2006), I believe the reason for this is that in designing content that 
could be delivered both using manipulatives (for the intervention group) and not (for the control group) I effectively created a scenario in which students could draw on their understanding of how the manipulatives would work, and did not need to have hands-on contact to envisage their utilisation.

\section{Research rigour}

I enjoyed the quantitative analysis (being a maths teacher), and had huge excel spreadsheets of calculations of correlations and rankings. However I found it hard to keep track of my calculations and would come back to my work the following day with no recollection of what, for example, I had correlated with what, even though at the time it seemed perfectly clear. I had to recalculate the analysis of errors made in the pre- and post-tests several times because I seemed to be incapable of labelling data or filing it accurately. Other failings include not charging up the voice recorder before one session so that I had no record of the entire lesson, and confusion between one group and another causing me to think that I had done something with one group already which I had not. I was also very poor at writing up my reflections on the lessons, as at the time they seemed so self-evident, but over time the nuances were lost.

\section{Uncertainty}

The advantage of control that I referred to above is set off by the overwhelming uncertainty of having to make every decision and interpretation. I longed for the security of a statistically significant rho or a disconfirming t-test. This is inherent to some extent with action research as it is impossible to measure the effect of researcher-learning, but I think that my focus was particularly hard to evaluate.

\section{Conclusions}

Action research is a dynamic and empowering way to study aspects of one's own practice. In investigating the use of manipulatives in mimicking algebraic algorithms I unpicked my own understanding and strengthened my knowledge. In working closely and intensely with small groups I came to understand not just what they could and could not do, but where their problems lay, how deeply ingrained their problems were and what was likely to provoke further difficulties. This helped me improve my pedagogy more generally, by focusing on intuitive and informal methods and giving students the opportunity to really explore misconceptions. I came to appreciate that the 
reason students struggle with algebra is because it is based on an assumption of fluency with logic and arithmetical conventions that for some students does not exist. As a result of this investigation I have developed manipulatives in the form of playing cards that use the idea of cards dealt face up as cards whose value is known, and cards dealt face down as cards for which there is a value, but the value is not yet known - the variable. I have been able to reproduce most of the early algebra curriculum using this idea, and it has been very well received where it has been trialled. It may even be that I investigate its value further by undertaking more action research!

It may seem that the outcomes of this research project are fairly trivial, and to the extent that a group of children worked on a different way of learning using manipulatives for a very short period of their schooling, they are. However the real point of action research is in the effect on the researcher, allowing her to step away from the dominant voice and take responsibility for the opportunity of affecting the lives of young people. Viewed in this way, the outcomes for me in developing praxis, the merging of theory and practice, have affected the way I teach in every possible respect.

\section{Appendix 1}

\section{Attitudes towards algebra inventory}

\section{Reference number}

Directions: This inventory consists of statements about your attitude toward Algebra. There are no correct or incorrect responses. Read each item carefully. Please think about how you feel about each item and tick the column that most closely corresponds to how each statement describes your feelings. Please answer every question.

\begin{tabular}{|c|c|c|c|c|c|}
\hline \multirow{2}{*}{ 1. Algebra is a very worthwhile and necessary subject. } & Strongly & Disagree & Neither & Agree & Strongly \\
\hline & & & & & \\
\hline 2. I want to develop my algebra skills. & & & & & \\
\hline 3. I get a great deal of satisfaction out of solving algebra & & & & & \\
\hline 4. Algebra helps develop the mind and teaches a person to think. & & & & & \\
\hline 5. Algebra is important in everyday life. & & & & & \\
\hline $\begin{array}{l}\text { 6. Algebra is one of the most important subjects for people to } \\
\text { study. }\end{array}$ & & & & & \\
\hline $\begin{array}{l}\text { 7. Algebra lessons will be very helpful no matter what I decide to } \\
\text { study. }\end{array}$ & & & & & \\
\hline 8. I can think of many ways that I use algebra outside school. & & & & & \\
\hline 9. Algebra is one of my most dreaded subjects. & & & & & \\
\hline
\end{tabular}




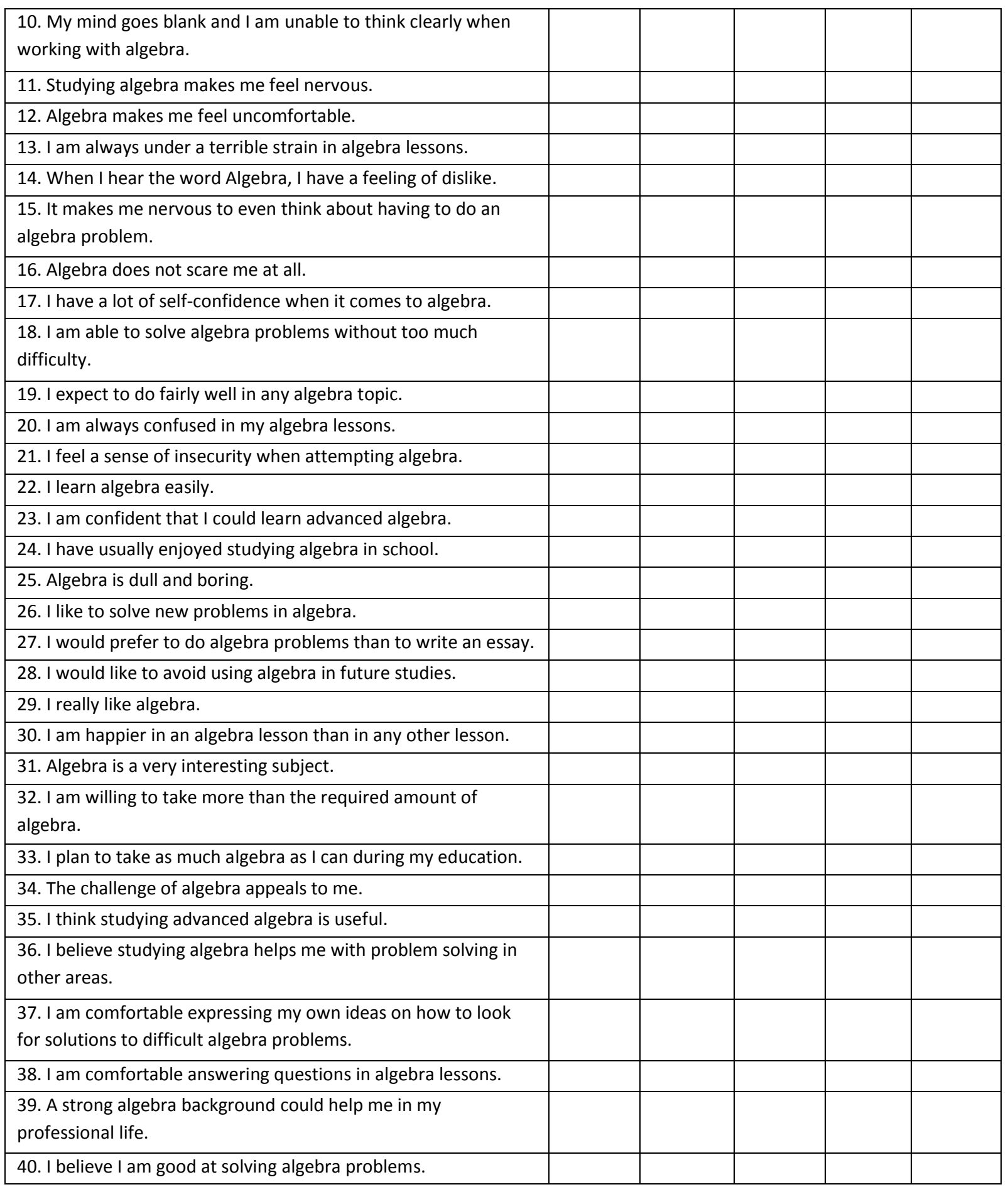

(C) Martha Tapia 1996 


\section{Exercises and Discussion Questions}

1. What are the problems for a teacher investigating her own practice? How can she attempt to overcome these problems?

2. Suggest a positivist approach to seeing whether the use of manipulatives has a positive effect on student progress, and an interpretivist approach. What do you think are the advantages and disadvantages of each?

3. One of the problems I encountered was in designing material that linked concrete objects to abstract ideas. To what extent do you think the abstract nature of algebra makes attempts to harness lived experience futile?

4. The literature is divided over whether it is better to teach algebraic notation before, during or after concrete intervention. What are the advantages and disadvantages of leaving notation until after the student has made sense of the situation?

5. Action research is moulded by the researcher and participants, but this means that there are no 'right answers'. Does this make it weaker as a research approach?

6. Am I right to claim that this action research project was more than just 'technical' or 'practical' (an attempt to find what works better) and is actually 'emancipatory' (goes towards researcher and student liberation from the status quo)?

\section{References}

Bell, J. (2005). Doing your research project, Fourth Edition. Maidenhead: Open University Press.

Bourdieu, P. (1973). Cultural reproduction and social reproduction. In R. Brown (Ed.), Knowledge, education, and cultural change: Papers in the sociology of education. London: Tavistock Publications, (pp.71-112).

Bruner, J. (1966). Toward a theory of instruction. Cambridge, MA: Belknap Press.

Carr, W., \& Kemmis, S. (1986). Becoming critical: Education, knowledge and action research. London: The Falmer Press.

Curtis, F. (2015). Challenge: always a good thing? Proceedings of the British Society for Research into Learning Mathematics, 35, (2), 7-12. 
Kemmis, S. (1993). Action research and social movement: A challenge for policy research. Education Policy Analysis Archives, 1, (1).

McNiff, J., \& Whitehead, J. (2010). You and your action research project. Oxford: Routledge.

Merrett, F. (2006). Reflections on the Hawthorne effect. Educational Psychology 26 (1), 143-146.

Mullis, I., Martin, M., Foy, P., \& Arora, A. (2012). TIMSS 2011 international results in mathematics. Chestnut Hill, MA: TIMSS and PIRLS International Study Centre, Boston College.

Norton, L. (2009). Action research in teaching and learning. Abingdon, Oxon:Routledge.

Piaget, J. (1952). The child's conception of number. London: Routledge \& Kegan Paul Ltd.

Tapia, M., \& Marsh, G. (2004). An instrument to measure mathematics attitudes. Academic Exchange Quarterly, 8 (2). 